\title{
A team-based competition for undergraduate medical students to learn radiology within the virtual world Second Life
}

Teodoro Rudolphi-Solero ${ }^{1}$, Alberto Jimenez-Zayas², Rocio Lorenzo-Alvarez ${ }^{3}$, Dolores Domínguez-Pinos², Miguel Jose Ruiz-Gomez ${ }^{2}$ and Francisco Sendra-Portero ${ }^{2^{*}}$ (i)

\begin{abstract}
Background: A multi-user competitive game within the virtual world Second Life for undergraduate radiology learning was adapted for team participation. This study aimed to assess student perception, impact on learning, and eventual correlation of game results with post-exposure tests and course grades.

Methods: The game consisted of six weekly stages, dedicated to thoracic, abdominal, and musculoskeletal radiological anatomy and semiology. Participants had several days a week to review self-guided radiology educational content and then complete individual multiple-choice tests and solve team tasks to progress through the game's ranking. Additionally, they completed a cognitive load test, a questionnaire about the experience and a post-exposure knowledge test.

Results: Fifty-two students organised into 13 teams participated in the game and assessed different aspects of the experience with a mean score $\geq 7.8$ on a 10-point scale, highlighting the participation of the teacher (9.3 \pm 1.1$)$, the educational contents $(8.8 \pm 1.4)$ and the usefulness for their education $(8.7 \pm 1.4)$. Participants obtained better postexposure test results $(p<0.007)$ and better course grades $(p<0.021)$ than non-participants did.

Conclusion: A multi-user game adapted to team competition to learn radiology in Second Life was very positively perceived by third-year medical students, who highly valued its content, organisation, and usefulness for their training. Most of the participants agreed that they had collaborated as a team and that playing in competitive environments helps them learn better. The best post-exposure and academic results compared to non-participating students indicate the potential impact of the game on learning.
\end{abstract}

Keywords: Game-based learning, Virtual worlds, Medical education, Medical students, Radiology

\section{Keypoints}

- Competing as a team in the virtual world Second Life is an engaging and dynamic blended learning method for learning radiology alongside the undergraduate formal course.
- Medical students appreciate the content, organisation, and educational utility of a game such as the League of Rays and find that competing in teams helps them learn better.

- Compared to individual competition, competing in teams has the advantages of promoting collaborative learning and responsibility in collective work.

\footnotetext{
*Correspondence: sendra@uma.es

${ }^{2}$ Department of Radiology and Physical Medicine, School of Medicine,

University of Málaga, Málaga, Spain

Full list of author information is available at the end of the article
}

\section{Springer Open}

(c) The Author(s) 2021. Open Access This article is licensed under a Creative Commons Attribution 4.0 International License, which permits use, sharing, adaptation, distribution and reproduction in any medium or format, as long as you give appropriate credit to the original author(s) and the source, provide a link to the Creative Commons licence, and indicate if changes were made. The images or other third party material in this article are included in the article's Creative Commons licence, unless indicated otherwise in a credit line to the material. If material is not included in the article's Creative Commons licence and your intended use is not permitted by statutory regulation or exceeds the permitted use, you will need to obtain permission directly from the copyright holder. To view a copy of this licence, visit http://creativecommons.org/licenses/by/4.0/. 


\section{Introduction}

Radiology education is an important part of the undergraduate medical curriculum, and the use of e-learning in the teaching of radiology in medical schools is on the rise [1]. Therefore, it is important to explore the applicability of innovative technologies and approaches to teaching and the improvements they bring to learning. Digital games have an interesting educational value, as they can engage medical students in their learning and offer them unique insights on the strengths and weaknesses of their knowledge [2]. Game-based learning, with successive rules, rewards, and achievements to motivate medical students, is gaining impact compared to other traditional training techniques [3-6]. Competition is a core element in educational games [7]. Competitive learning techniques improve academic outcomes and can strengthen cooperation among medical students [8]. When teams of students compete with others, learning techniques combine group rewards with individual responsibility and encourage collaboration. Competition and collaboration together have a recognised positive effect on learning [7].

Virtual worlds are three-dimensional spaces reproduced on the computer screen where users interact through a representation of themselves called an avatar, through which the user can move, interact, and communicate with others [9]. There is great interest in research on education in virtual worlds [10], particularly in the possibilities they offer to develop learning games within them [11-13]. Second Life, launched by Linden Research Inc (San Francisco CA. USA) in 2003, is the most active virtual world in education with healthcare professionals [14]. Interesting education experiences have been carried out in Second Life with patients [15-17], physicians $[18,19]$, and medical students [20-22]. Users can communicate within Second Life via voice and written chat or, alternatively, sending notecards (in-world written messages that remain stored in the inventory of the receiving avatar, recording the date and time of sending and the avatar that created it). The objects in Second Life are composed of primary objects or prims, which can reproduce a Web page on one or more of their faces. This resource can be used as a presentation system for educational content in Second Life, through panels reproducing simple web pages, created from PowerPoint presentations, with backward and forward buttons [23].

In 2011, a virtual space named "The Medical Master Island" was acquired in Second Life to develop educational innovation activities on radiology [24]. Various learning activities with medical students were carried out to explore the feasibility of synchronous teaching sessions and asynchronous tasks [25], evaluate the perception of the students [26], and compare the learning outcomes of seminars held in Second Life and in real life [27]. In 2015, a multi-user competitive game was designed within Second Life, based on self-guided presentations and multichoice tests. The game, called the League of Rays, forms the basis of this study. It was designed as an individual competition during the four-month Radiology course, taught in the third year of medicine. Several editions have been previously held, with voluntary [28] and compulsory participation. The authors hypothesise that team competition in a learning game like League of Rays can be carried out with good acceptance by students, favouring collaborative work and providing positive learning outcomes. This study aims to explore the participation of student teams, adapting the rules of the League of Rays game, evaluating students' perception, impact on learning and the eventual correlation of game results with mid-term knowledge tests and course grades.

\section{Materials and methods}

\section{The virtual environment}

The Medical Master Island reproduces a university campus, with a central esplanade surrounded by trees and walkways, educational buildings, open-air auditoriums (Fig. 1), and underwater settings (caves, palaces, submerged cellars, etc.) used to give a playful aspect to some learning activities.

\section{Participants}

In February 2019, the game was introduced as a voluntary online activity for students enrolled for the first time in the four-month Radiology course. Students were informed that their participation would have no effect on their grades. They were invited to 2-h training sessions on Second Life, held on March. Several PDF files were provided with instructions for using Second Life and the rules of the game. Those students who wanted to participate in the game had to propose together with a partner, and the organisation randomly unified the pairs into teams of four. Participants were asked to submit their team name and colour, logo image, and choose a captain.

This study carried out within the framework of the Educational Innovation Project of the University of Malaga \# PIE17-113 received the corresponding approval from the Vice-Rector's Office for Teaching and Research Staff. The students gave their explicit consent when they voluntarily agreed to participate. No additional ethical permission was needed.

\section{Structure and organisation of the game}

The League of Rays team-based game was held from April 1 to May 19, 2019, organised in 6 stages of 7 days, from Monday to Sunday. Between the second and third stages, the game was interrupted for the Easter holidays. The first three stages were dedicated to radiological 


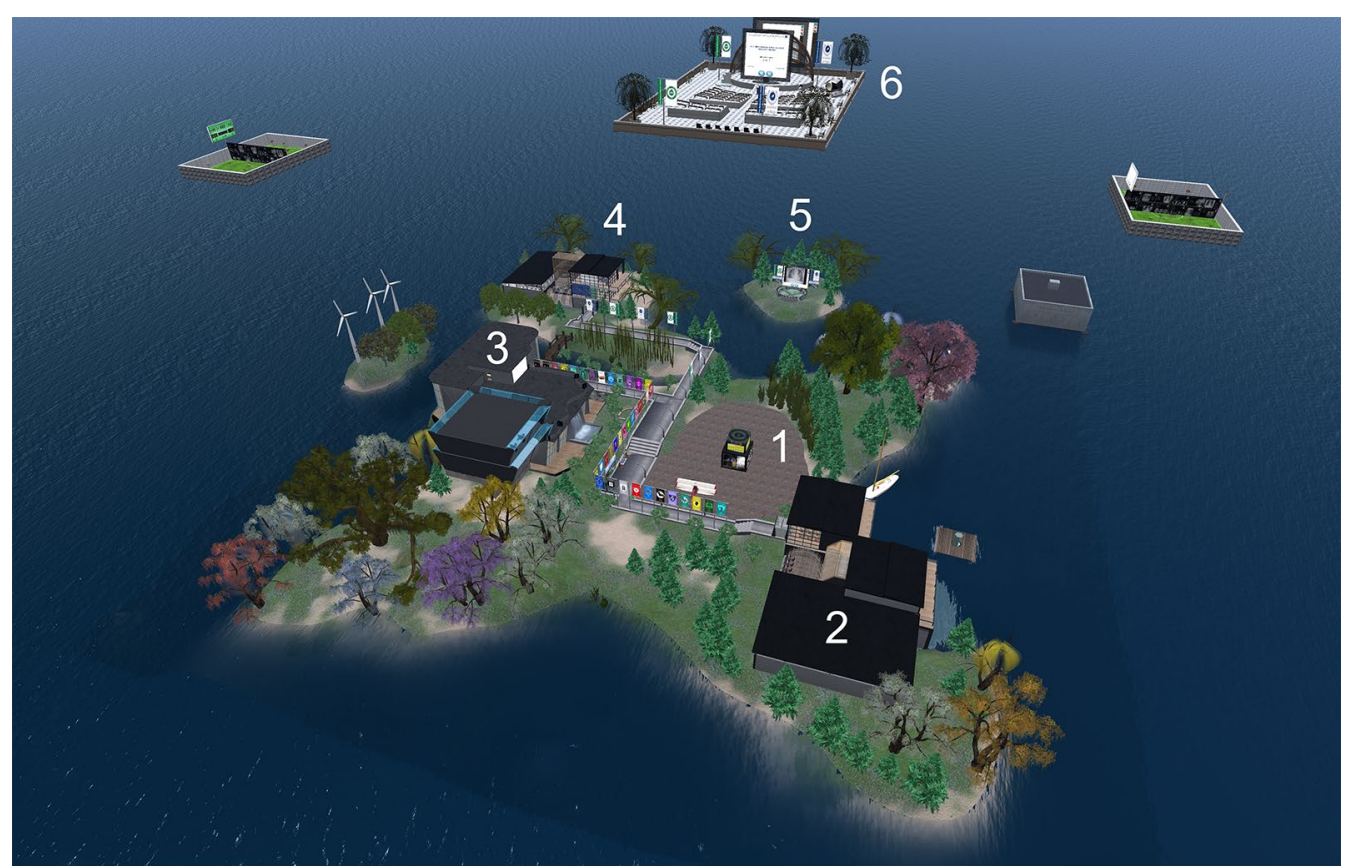

Fig. 1 Aerial view of the Medical Master Island, in which the following are indicated: (1) the central esplanade, next to the arrival point; (2) the postgraduate building; (3) the Medical Master Conference Center; (4) the undergraduate building; (5) a small open-air auditorium, on an islet; and (6) a floating auditorium, in the air

anatomy and the next three to radiological semiology. Thorax, abdomen, and musculoskeletal were treated successively in each 3-week block.

During the first 5 days of each stage, educational contents, elaborated from the syllabus and seminars of the course, and online resources with owned copyrights were presented in a set of 3 panels with 50 self-explanatory slides each. Each week, 6 sets of panels were arranged in the central esplanade of the island, available continuously for participants (Fig. 2). On the afternoon of the fifth day, the educational panels were replaced by single panels with 15 multi-choice questions. A database of 180 slides with multi-choice questions, 30 questions for each thematic block, was used for this purpose. Twelve test variants were elaborated, homogeneously distributing the 30 corresponding questions, so that each of them was in 6 test variants. Each week, a test variant was assigned to each participant, who had to answer it by sending a notecard to the teacher's avatar. Test variants were not repeated within the same team. Correct answers added one point and incorrect answers subtracted 0.25 points for each participant. The teams, ordered by the sum of their members' scores, received from 0 to 12 points according to their position. The points accumulated by each team determined the classification after each stage. The test panels were arranged in various places (among the trees, in the sky or under water), to give variability to the game (Fig. 2). In the last three stages, dedicated to semiology, an additional task called "Normal or Pathological" (N/P) was included, consisting of a panel with 20 radiographs, of which 12 were normal. The teams had to correctly diagnose pathological cases and identify normal ones and their captain had to send the notecard with the answers. Zero to 12 additional points were assigned to the teams, using the same methodology as in the individual tests. In this way, the maximum points achievable in the competition were 108 ( 12 points $\times 6$ tests $\times 3$ tasks). Figure 3 shows a complete diagram of the game to facilitate understanding. The evolution of the contest was publicised on the virtual campus (Moodle platform) of the Radiology course. All participants received a certificate, specifying their participation in an educational innovation project for $18 \mathrm{~h}$.

\section{Assessment of the impact on learning}

A 9-point Likert scale from 1 (very, very low mental effort) to 9 (very, very high mental effort) [29] was used to evaluate the cognitive load related to the review of the teaching content, the performance of the game tests, and the use of Second Life, at the end of the three blocks corresponding to anatomy and semiology. The test scores of each stage made it possible to measure the shortterm knowledge profile of the participants. The correct answers were not provided during the game. One month 


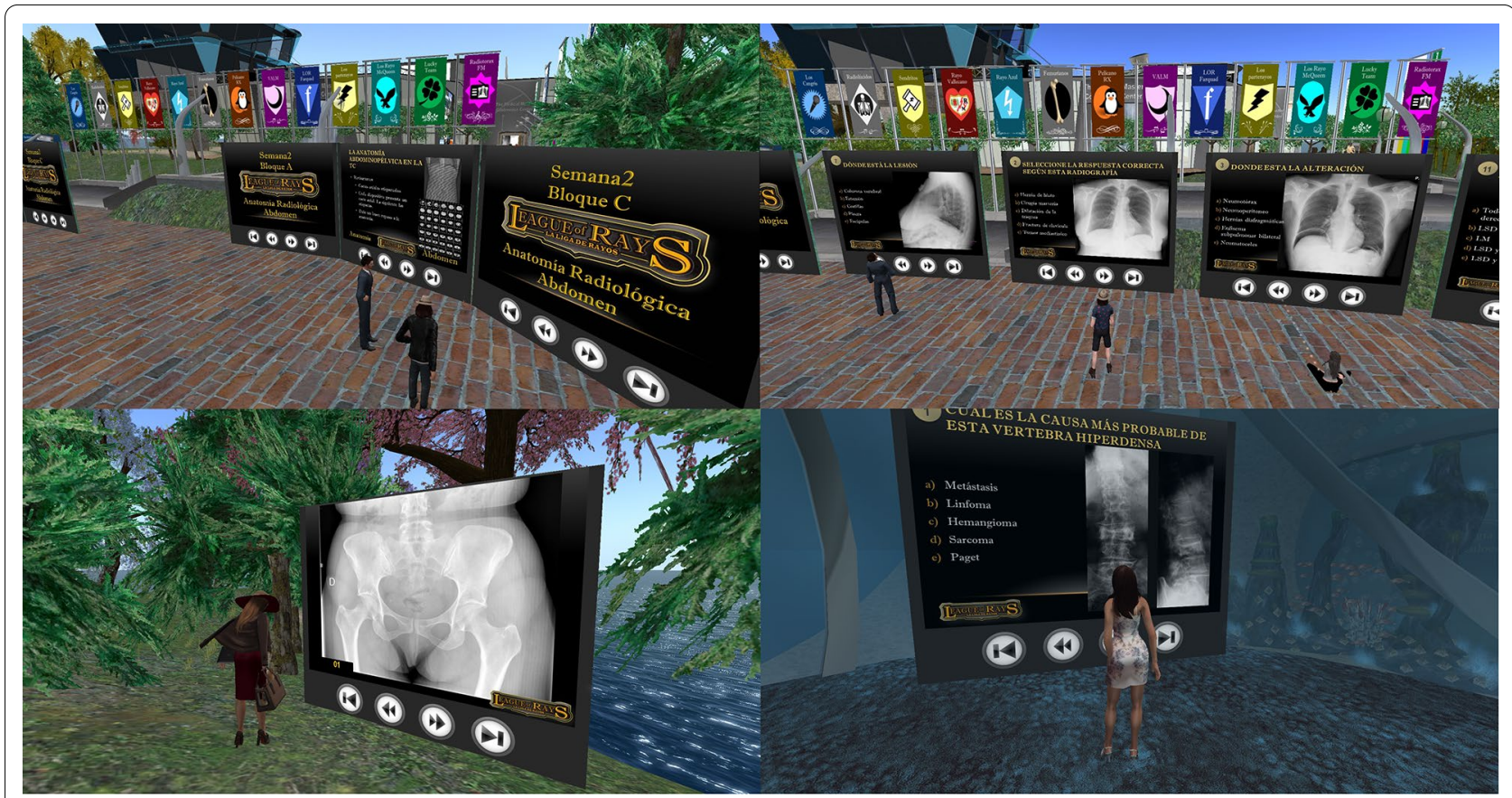

Fig. 2 Different scenes during the League of Rays game. Top left: students viewing a set of three learning panels on radiographic anatomy of the abdomen. Top right: Students in front of panels with weekly tests on the central esplanade. Bottom left: a student in front of an N/P task located between the trees. Bottom right: student conducting a weekly test at an underwater facility

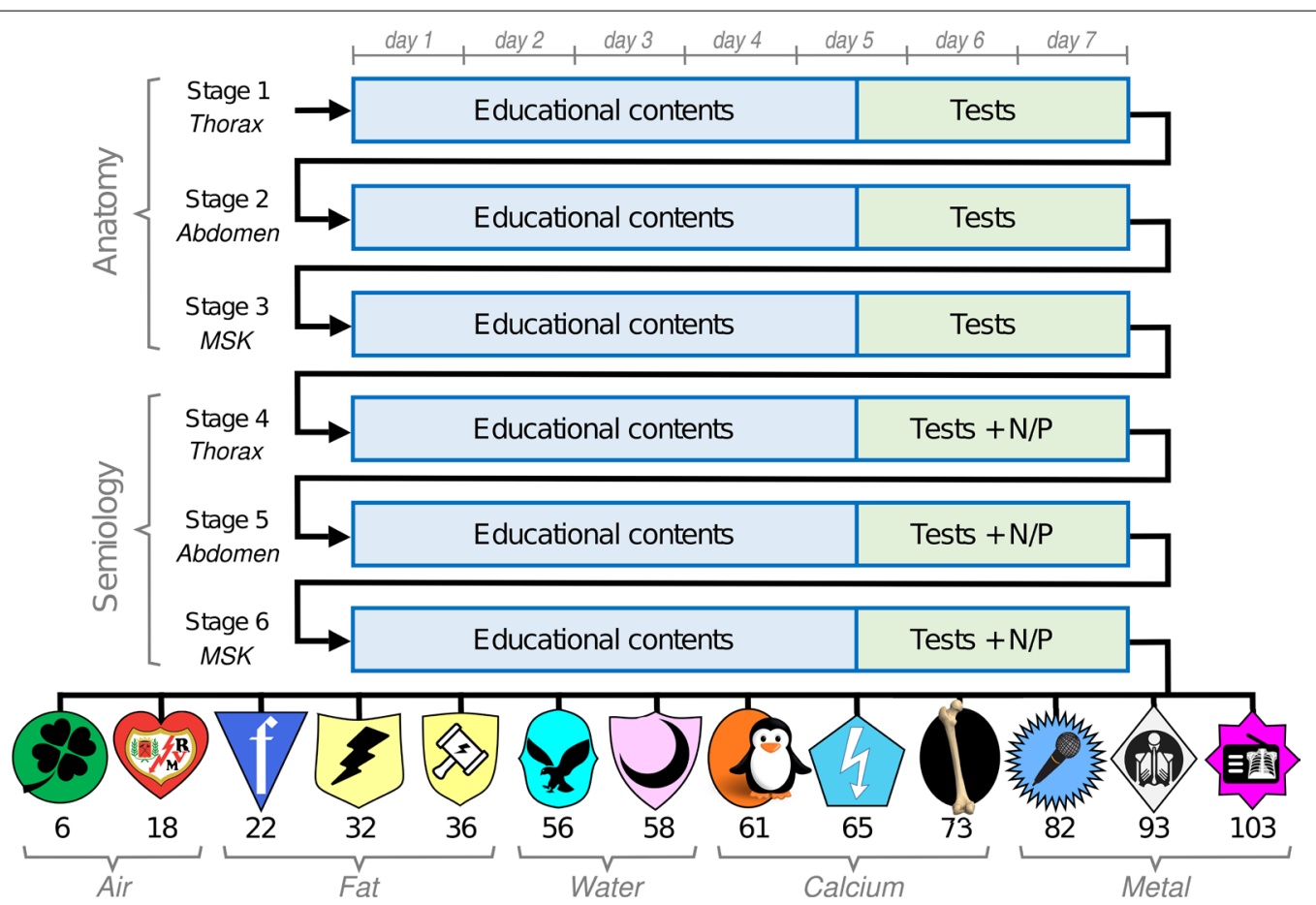

Fig. 3 Diagram representing the flow of the Team-based League of Rays game. The 13 teams with the points achieved at the end of the competition are shown below, together with the badge that represents them. Test: Multi-choice test of 15 questions. N/P: Task "Normal or Pathological" 
after the game ended, all the students in the course were invited to a review seminar in the classroom, where the certificates and prizes of the participating teams were publicly given. The 180 questions of the game were reviewed except for 60 questions (10 randomly selected from each stage) that integrated a post-exposure test with $30 \mathrm{~s}$ to answer each question. Additionally, course scores were recorded to correlate with game scores. The results of participants and non-participants were compared.

\section{Evaluation of the experience}

Students who participated in the game were asked to complete an experience evaluation questionnaire, based on that from previous studies [28], consisting of 23 statements with answers on a five-point Likert scale (7 about Second Life, 8 about the game, 4 about the presentation of the different stages and 4 about the multi-choice tests), an evaluation of 1 to 10 points of various aspects of the project and a text box to add open comments (See Additional file 1: Appendix 1). No personal identification was included in the evaluations, and they were analysed anonymously.

\section{Data analysis}

Data were organised in Excel 2013 files (Microsoft, Redmond, WA, USA), and the SPSS statistical package, version 24 (IBM Corporation, Armonk, NY, USA), was used

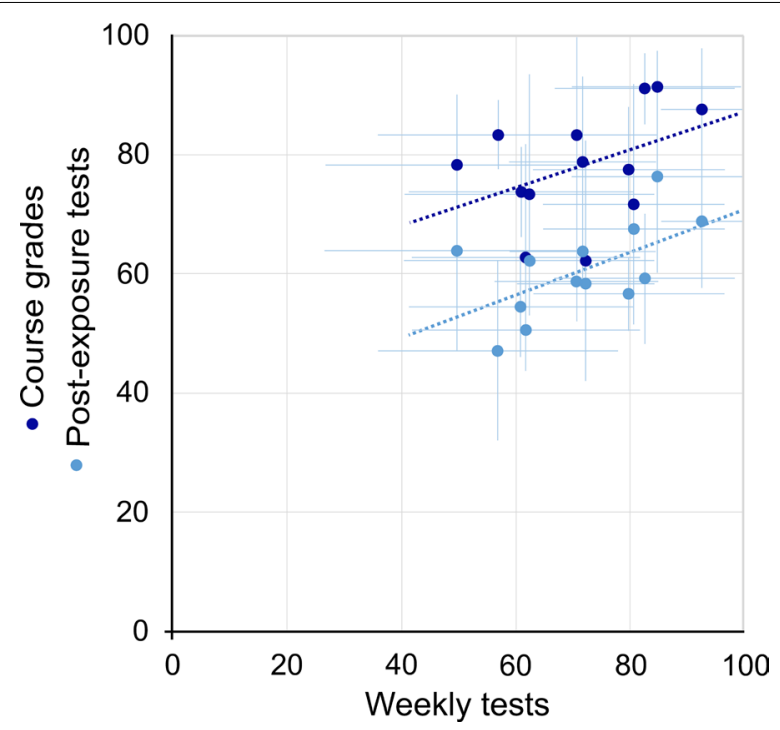

Fig. 4 Graph showing the correlation of the results obtained by each team in the weekly game tests with the results obtained in the post-exposure tests (light blue points; Pearson's coefficient $=0.572$ ) and with the course grades (dark blue points; Pearson's coefficient $=0.425$ ). The data are the average scores obtained by teams, expressed as a percentage. Error bars represent the standard deviation for statistical analysis. The Student's t test for unpaired samples was used to assess the differences between participants and non-participants in the post-exposure test and course grades. Pearson's correlation coefficient was used to assess the correlation between the game tests with post-exposure tests and course grades. Statistical significance was accepted when a probability of error $p<0.05$ was obtained.

To validate the questionnaire, Cronbach's $\alpha$ test was applied to the three constructs of the questionnaire: the student's experience in Second Life, the student's experience in the game, and the overall evaluation of the project. Kendall's $\mathrm{t}$-b test was used to evaluate the validity of the questions in each construct, indicating the agreement between the students when answering each item, with an accepted level of significance for $p<0.05$. The adequacy of the analytical factor model was evaluated with the Kaiser-Meyer-Olkin (KMO) test.

The open comments included in the questionnaire were analysed through collaborative systematic coding by group consensus agreement [30], considering the codes obtained in previous studies on League of Rays [28]. In a first consensus meeting, four first-layer codes were established: positive, negative, suggestions, and team. The last, indicating that the comment made specific reference to teamwork. Second-layer subcodes were proposed and finally agreed upon in a second consensus meeting. The same comment could contain more than one different codes and/or subcodes.

\section{Results}

\section{Participation and evolution of the game.}

Fifty-two students out of 185 (28.1\%), organised into 13 groups of 4 students, participated in the game. Table 1 shows the results of the weekly tests and the N/P tasks, together with the final score of each team. The correlation between the game score and the sum of accumulated correct answers for each team was excellent (Pearson coefficient $=0.973$ ). There were 21 undelivered weekly tests and 4 undelivered N/P tasks.

\section{Impact on learning}

The questions about cognitive load during the anatomy and semiology stages were answered by $46(88.5 \%)$ and 31 (59.6\%) participants, respectively. The mental effort to use Second Life was significantly lower during the first three weeks (cognitive load $=3.8 \pm 2.5$ vs $5.7 \pm 2.0$; $p<0.001)$. No significant differences were found in the mental effort involved in reviewing the teaching content $(5.7 \pm 1.1$ vs $5.8 \pm 1.5)$ or performing the tests $(6.0 \pm 1.8$ vs $6.5 \pm 1.6)$. The mean percentage of correct answers in the game tests was higher in the three stages of anatomy than in the three stages of semiology $(75.5 \pm 19.5$ 
Table 1 Results of the 13 participating teams, classified according to the final classification

\begin{tabular}{|c|c|c|c|c|c|c|c|}
\hline \multirow[t]{2}{*}{ Teams } & \multicolumn{3}{|c|}{ Weekly tests } & \multicolumn{3}{|c|}{ N/P tasks } & \multirow[t]{2}{*}{ Final points } \\
\hline & Hits $^{\mathrm{a}}$ & $(\%)^{a}$ & Test not delivered & Hits $^{b}$ & $(\%)^{b}$ & $\begin{array}{l}\text { Task not } \\
\text { delivered }\end{array}$ & \\
\hline Radiotorax FM & 333 & 92.5 & 0 & 55 & 91.7 & 0 & 103 \\
\hline Radiolúcidos & 297 & 82.5 & 0 & 54 & 90.0 & 0 & 93 \\
\hline Los Cangris & 35 & 84.7 & 0 & 51 & 85.0 & 0 & 82 \\
\hline Femurianos & 275 & 76.4 & 1 & 44 & 73.3 & 0 & 73 \\
\hline Rayo Azul & 239 & 66.4 & 1 & 46 & 76.7 & 0 & 65 \\
\hline Pelicano RX & 254 & 70.6 & 0 & 45 & 75.0 & 0 & 61 \\
\hline VALM & 258 & 71.7 & 0 & 44 & 73.3 & 0 & 58 \\
\hline Los Rayo McQueen & 278 & 77.2 & 1 & 24 & 40.0 & 1 & 56 \\
\hline Sendritos & 210 & 58.3 & 1 & 40 & 66.7 & 0 & 36 \\
\hline Los Parterayos & 215 & 59.7 & 1 & 41 & 68.3 & 0 & 32 \\
\hline LOR Farquad & 176 & 48.9 & 5 & 31 & 51.7 & 0 & 22 \\
\hline Rayo Vallecano & 149 & 41.4 & 4 & 29 & 48.3 & 0 & 18 \\
\hline Lucky Team & 145 & 40.3 & 7 & 0 & 0.0 & 3 & 6 \\
\hline
\end{tabular}

N/P: Normal/Pathological

${ }^{a}$ Number of correct answers for weekly tests on a maximum of 360 points ( 15 points $\times 6$ weeks $\times 4$ participants)

${ }^{b}$ Number of correct answers of the N/P tasks on a maximum of 60 points ( 20 points $\times 3$ tasks)

Table 2 Correct questions in the tests each week (mean \pm standard deviation) during the game, together with the number of tests not delivered

\begin{tabular}{|c|c|c|c|c|}
\hline & \multicolumn{2}{|l|}{ Correct questions } & \multicolumn{2}{|c|}{$\begin{array}{l}\text { Not } \\
\text { delivered }\end{array}$} \\
\hline & $\begin{array}{l}\text { (mean } \pm \text { standard } \\
\text { deviation) }\end{array}$ & $(\%)^{a}$ & $\bar{N}$ & $(\%)^{b}$ \\
\hline $\begin{array}{l}\text { Week 1. Thoracic } \\
\text { anatomy }\end{array}$ & $8.9 \pm 2.9$ & $59.6 \pm 19.6$ & 3 & 5.8 \\
\hline $\begin{array}{l}\text { Week 2. Abdominal } \\
\text { anatomy }\end{array}$ & $12.3 \pm 2.0$ & $82.0 \pm 13.4$ & 5 & 9.6 \\
\hline $\begin{array}{l}\text { Week } 3 \text { MSK } \\
\text { anatomy }\end{array}$ & $12.8 \pm 2.1$ & $85.3 \pm 13.8$ & 3 & 5.8 \\
\hline ANATOMY & $11.3 \pm 2.9$ & $75.5 \pm 19.5$ & 11 & 7.1 \\
\hline $\begin{array}{l}\text { Week 4. Thoracic } \\
\text { semiology }\end{array}$ & $10.4 \pm 3.2$ & $69.6 \pm 21.4$ & 5 & 9.6 \\
\hline $\begin{array}{l}\text { Week 5. Abdominal } \\
\text { semiology }\end{array}$ & $10.8 \pm 3.3$ & $72.0 \pm 21.9$ & 3 & 5.8 \\
\hline $\begin{array}{l}\text { Week 6. MSK semiol- } \\
\text { ogy }\end{array}$ & $9.6 \pm 2.6$ & $64.1 \pm 17.7$ & 2 & 3.8 \\
\hline SEMIOLOGY & $14.9 \pm 2.5$ & $68.5 \pm 20.5$ & 10 & 6.4 \\
\hline TOTAL & $10.8 \pm 3.0$ & $72.0 \pm 20.3$ & 21 & 6.7 \\
\hline
\end{tabular}

Bold values indicate results of the three weeks of anatomy, the three weeks of semiology or the total of six weeks, respectively

a Percentage calculated on 15 questions for each test

${ }^{b}$ Percentage calculated with respect to 52 weekly tests

$N$ Number of tests not delivered by students
Table 3 Correct questions in the "normal or pathological" tasks during the game, together with the number of tests and tasks not delivered

\begin{tabular}{|c|c|c|c|c|}
\hline & \multicolumn{2}{|l|}{ Correct questions } & \multicolumn{2}{|c|}{$\begin{array}{l}\text { Not } \\
\text { delivered }\end{array}$} \\
\hline & $\begin{array}{l}\text { (mean } \pm \text { standard } \\
\text { deviation) }\end{array}$ & $(\%)^{a}$ & $N$ & $(\%)^{b}$ \\
\hline Task N/P Chest & $13.3 \pm 3.7$ & $66.7 \pm 18.6$ & 1 & 7.7 \\
\hline Task N/P Abdomen & $15.0 \pm 3.7$ & $75.0 \pm 18.7$ & 1 & 7.7 \\
\hline $\begin{array}{l}\text { Task N/P Musculo- } \\
\text { skeletal }\end{array}$ & $14.9 \pm 2.5$ & $74.5 \pm 24.7$ & 2 & 15.4 \\
\hline TOTAL & $14.4 \pm 3.4$ & $72.0 \pm 17.0$ & 4 & 10.2 \\
\hline
\end{tabular}

Bold values indicate results of the total "normal or pathological" (N/P) tasks

a Percentage calculated on 20 questions for each task

${ }^{\mathrm{b}}$ Percentage calculated with respect to 13 tasks of each anatomical location, 39 intotal

$N$ Number of tests not delivered by students

vs $68.5 \pm 20.5 ; p=0.009$ ), although the lowest percentage of hits were obtained in thoracic anatomy (Table 2). The percentage of correct answers in the N/P tasks was $72.0 \pm 17.0$, with the lowest result in the chest tasks (Table 3).

The post-exposure test was carried out by 45 participants and 83 non-participants. Participants obtained 
Table 4 Percentages of correct answers and answers left blank in the post-test (mean \pm standard deviation) one month after the game

\begin{tabular}{|c|c|c|c|c|c|c|}
\hline & \multicolumn{3}{|c|}{ Correct answers } & \multicolumn{3}{|c|}{ Answers left balnk } \\
\hline & Participants & Non-participants & $p$ & Participants & Non-participants & $p$ \\
\hline Anatomy & $69.6 \pm 13.3$ & $65.5 \pm 11.7$ & 0.094 & $0.4 \pm 1.0$ & $0.9 \pm 1.7$ & 0.056 \\
\hline Semiology & $51.6 \pm 13.5$ & $40.8 \pm 12.2$ & $<0.001$ & $2.0 \pm 2.5$ & $3.7 \pm 4.7$ & 0.009 \\
\hline TOTAL & $60.6 \pm 11.9$ & $53.2 \pm 10.6$ & 0.001 & $2.4 \pm 3.2$ & $4.6 \pm 5.7$ & 0.007 \\
\hline
\end{tabular}

Participants $(n=45)$. Non-participants $(n=83)$

superior results than non-participants, with significant differences $(p=0.009)$ in the semiology questions (Table 4). The percentage of answers left blank for participants and non-participants was $2.4 \pm 5.2$ and $4.6 \pm 6.7$, respectively $(p=0.007)$. Forty-nine participants $(94.2 \%)$ and 96 non-participants $(72.1 \%)$ took the final examination in the June convocation, whose grades (mean percentage \pm standard deviation) were $79.2 \pm 15.3$ and $71.3 \pm 19.5$, respectively $(p=0.021)$. The mean of correct answers by teams showed a low correlation with the final grades (Pearson's coefficient $=0.425$ ) but moderate correlation with the post-exposure test (Pearson's coefficient $=0.572)($ Fig. 4).

\section{Students' perception}

Thirty-five participants (67.3\%) completed the evaluation questionnaire. The questionnaire presented high internal consistency in the three constructs that comprise it: the students' experience in Second Life (Cronbach alpha $=0.83$ ), the perception of the game (Cronbach $\alpha=0.81$ ), and the global evaluation of the project (Cronbach $\alpha=0.95)$. Kendall's $\mathrm{T}-\mathrm{b}$ test correlation matrices can be seen in Additional file 1: Appendix 3. Its analysis revealed a positive correlation between all pairs of variables with respect to the evaluation of the global experience $(\tau-\mathrm{b}>0.41 p<0.01)$ and with respect to participants' opinion about the experience in Second Life $(\tau-b>0.25$; $p<0.05$ in $19 / 21$ pairs combination). In exchange, the results were disparate regarding the perception of the students about the game, finding a positive correlation between variables 8,9 , and 10 , related to the design, information, and the adequacy of the contents to medical training $(\mathrm{\tau}-\mathrm{b}>0.34 ; p<0.05)$. In the factor analysis of the questionnaire, the results indicated that the sampling adequacy for the items related to the students' experience in Second Life was moderate (KMO index $=0.743$ ), for the items related to the students' perception of the game it was medium (KMO index $=0.612$ ), and for the overall evaluation of the project it was excellent (KMO index $=0.902$ ). The opinion of the students about Second Life was positive in general (mean values $\geq 4.0 \pm 1.0$
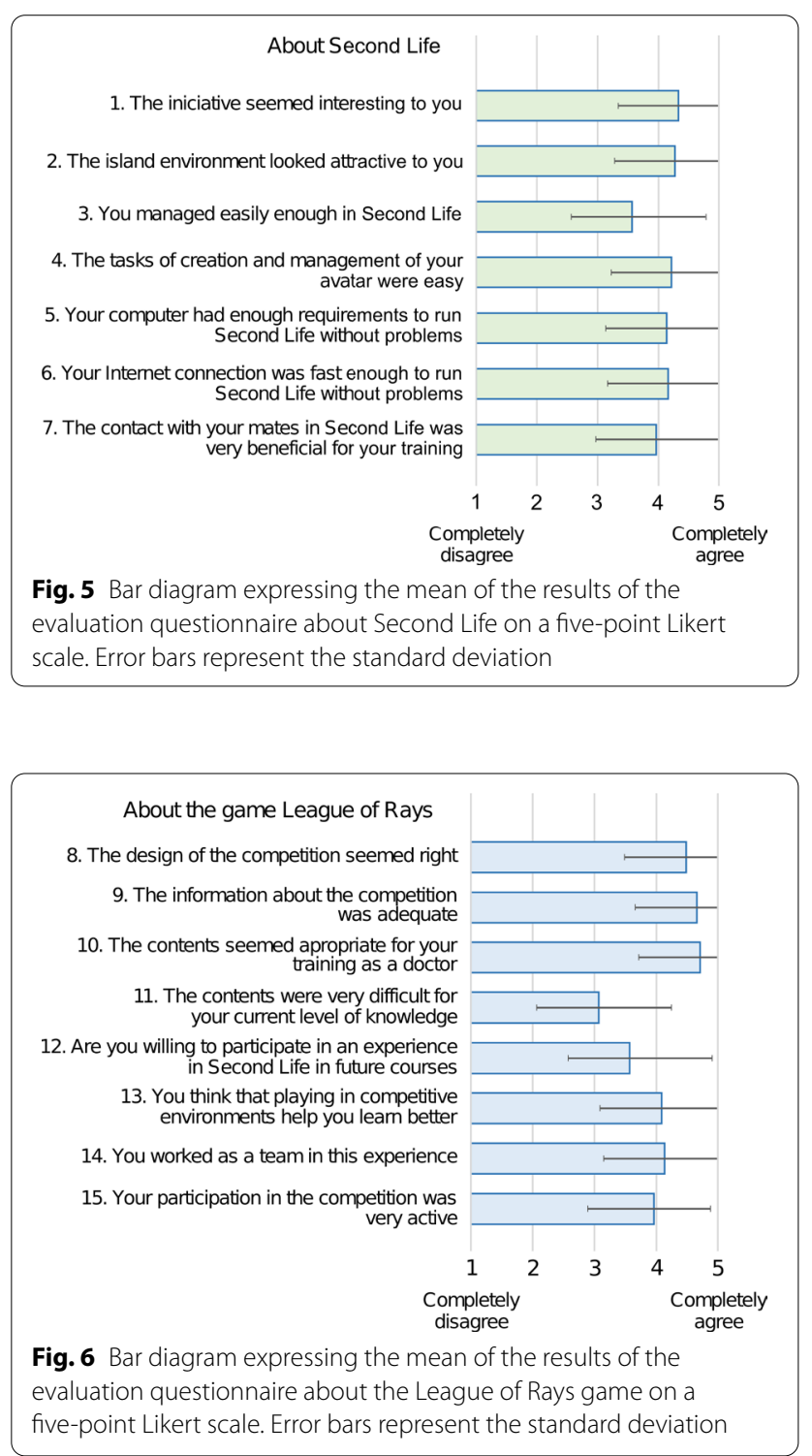

points on a five-point Likert scale), except for the statement "you managed easily enough in Second Life", to which 8 students (23\%) disagreed (responses 1-2), obtaining a mean value of $3.6 \pm 1.2$ (Fig. 5). The opinion 


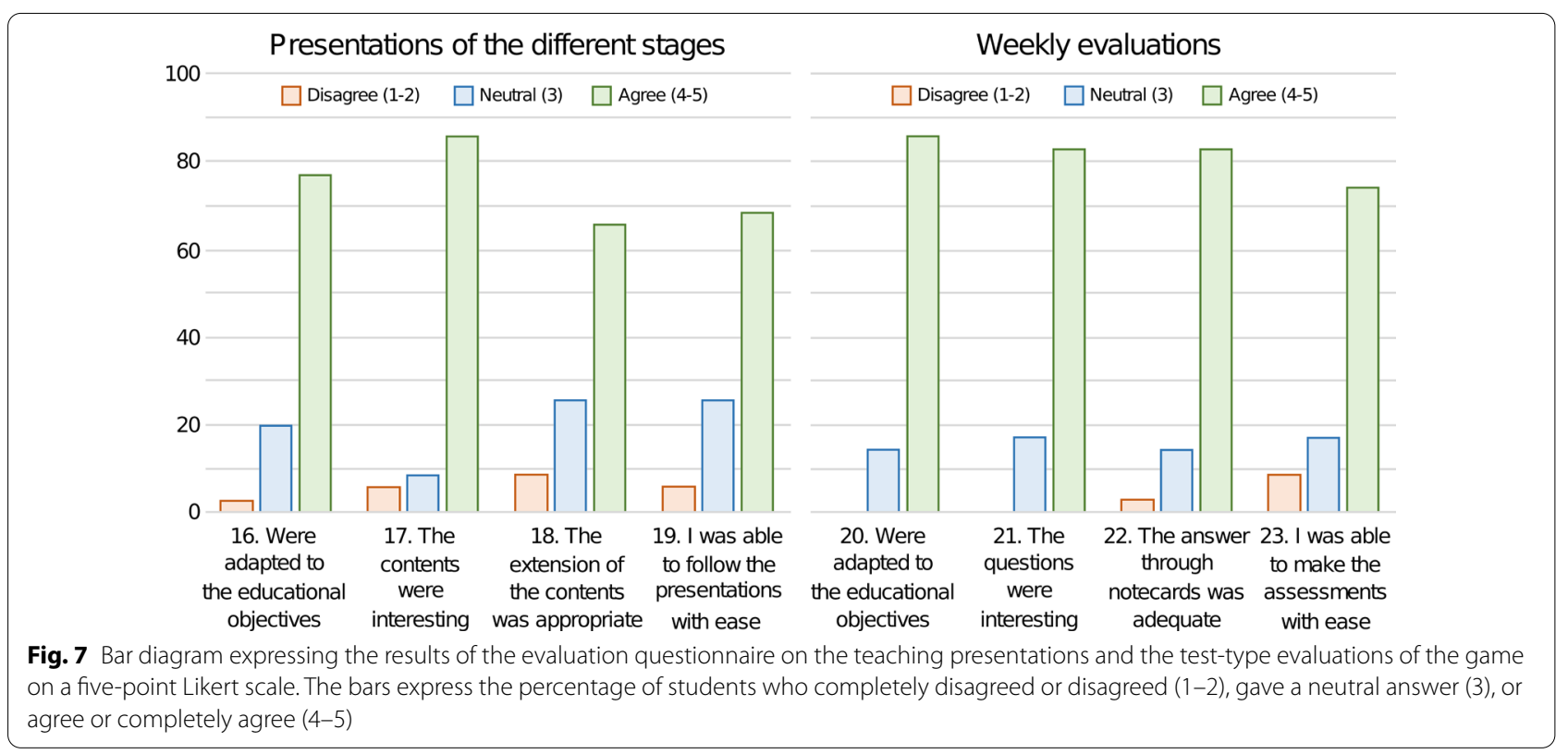

Table 5 Results of the global evaluation of the experience

\begin{tabular}{ll}
\hline Items & Scores \\
\hline The experience globally & $8.1 \pm 1.3$ \\
The organisation of the project & $8.6 \pm 1.2$ \\
The environment of the island & $8.6 \pm 1.7$ \\
Educational content & $8.8 \pm 1.4$ \\
The usefulness for your education & $8.7 \pm 1.4$ \\
The teacher & $9.3 \pm 1.1$ \\
Interaction with peers & $7.8 \pm 2.0$ \\
The presentations & $8.4 \pm 1.4$ \\
The evaluations & $8.2 \pm 1.3$ \\
Connectivity to Second Life & $7.9 \pm 1.9$ \\
\hline
\end{tabular}

The results represent the mean and standard deviation of 35 questionnaires for each item on a scale of 1 to 10

of the students about the game (Fig. 6) was very positive in terms of design, information, and the adequacy of the contents for medical training (mean values $\geq 4.5 \pm 0.7$ ). The participants agreed (answers 4-5) in having worked as a team during the game and in learning better in competitive games by $83 \%$ and $74 \%$, respectively. There was some dispersion in the answers about the difficulty of the contents, $34 \%$ agreed that they were difficult, $23 \%$ gave a neutral answer (3), and $43 \%$ did not find them difficult. Most of the students found the educational presentations and the evaluations during the game interesting, appropriate to the learning objectives, adequate, and easy to follow or perform (Fig. 7). Finally, the qualification of the experience, from 1 to 10 points, obtained very positive values (mean values $\geq 7.8$ ), highlighting the teacher, the educational content, and the usefulness for their training (Table 5).

Fourteen questionnaires (40\%) included open comments (see Additional file 1: Appendix 2). Ten of them included positive comments; 8 were subcoded as appreciation, since they included expressions such as "great initiative", "very interesting", or "highly recommended"; 7 reflected aspects related to the formative nature of the experience, with expressions such as "I have learned a lot", "great help to practice with cases" or "it has helped me to understand radiology"; 5 were subcoded as fun, as students found it an entertaining or fun learning method. Other positive comments included words of thanks, availability to participate in future editions, and motivation, expressly indicating this aspect of the experience. Some participants included several positive subcodes in their comment, for example: "I think that learning through competition is something that young people are very interested in. Generally, we do not like to lose, especially if it is against friends who we are going to see the next day in class. I think it is a very fun way to keep track of the subject and stay motivated throughout the semester". Five questionnaires included comments coded as negative. On four occasions, referred to the game's schedule, indicating that it ended near the examination period. Other negative subcodes were technical limitation to handle Second Life, content difficulty, lack of time due to having a lot of work with other courses. Comments coded as suggestions were found in eight questionnaires. Four of them proposing rules of the game, some almost describe a completely different game, others suggest 
an earlier schedule. Finally, there were four comments coded as team: team-choice, indicating that teams should be chosen by the members; team-demand, referring to the fact that more demand for participation should be requested from the teams; team-help, expressing the help provided by their teammates to solve technical problems; or team-inconvenience, verbatim as follows: "... team play is somewhat more cumbersome than individual participation, but in the end the result has been good."

\section{Discussion}

Today's medical students, young adults of Generation Z, make extensive use of new media technologies [31], enjoy learning through them [32], and often use virtual platform games for entertainment [33]. Game-based radiology education is an exciting and innovative teaching method with numerous benefits, such as student engagement, social interaction, instant feedback, and a personalised learning environment [34]. The virtual world Second Life provides interesting perspectives to play simulation games with proven educational success [35-37]. Although the League of Rays is not a medical simulation game, but a contest developed on an imaginary island, which provides learning reinforcement on basic radiological anatomy and semiology. It has been well valued by medical students competing individually [28] and also by teams, as this study shows, with great recognition for the design and organisation of the contest, the educational content and the adaptation to their medical training. This team competition could be considered as a mandatory activity of the course, but when individual participation in League of Rays is mandatory, the acceptance of virtual world technology decreases, the opinion about the game worsens, and the average score in the game decreases (unpublished observations of the authors).

Radiology blended learning formats that include new pedagogical concepts and current technologies allow improving the performance, satisfaction, and engagement of medical students [38]. The League of Rays game provides educational contents devised to be both a review and a training complement to the formal Radiology course, in an attractive context, of active and dynamic participation. In addition, it allows students to know the strengths and weaknesses of their knowledge, a recognised value of digital games [2]. For example, the worst results of tests and game tasks were obtained in the thoracic stages. As chest radiology is essential in medical practice [39] and especially difficult to interpret due to overlapping anatomical structures [40], reinforcement of thoracic radiology learning is especially helpful.
The present study has shown that team participation in the League of Rays is feasible with a simple adaptation of the game rules, allowing teams to be classified with a scoring system highly correlated with the number of correct answers. Games in which teams of students compete are considered cooperative learning techniques that combine group rewards with individual responsibility, that is, collaboration with competition [7]. In the League of Rays, participants are encouraged to be responsible in their collective work, because if any of them get few hits or do not take the test, it will mean a decrease in their team in the classification. Success in obtaining the cooperation and commitment of the students depends on them, the game designers, and the educators [7]. Eighty-three percent of participants in this study agreed that they worked as a team. The motivation to participate in teams is perfectly reflected in one of the open comments: "... When knowledge is associated with positive experiences such as winning as a team or putting class theory into a game, everything becomes less serious and gives more ground to take this activity as something relaxed and entertaining". Other motivating elements for the participants in this study are the recognition (and good evaluation) of the design and organisation of the contest and the identification of the educational contents as a suitable learning reinforcement for their medical education. It would be interesting to follow these students to determine the possible influence on their choice of radiology as a medical specialty.

Competitive learning used to be associated with the traditional classroom and the competitive behaviour of students, being a subject of criticism [41]. Today, although it remains a topic of debate, competitive online learning through digital games is a powerful tool that can lead to favourable academic results [42]. Participants in the League of Rays performed better in post-exposure tests than non-participants $(p<0.007)$, especially at the expense of semiology questions. In addition, they obtained better final grades than their peers $(p<0.021)$. Both facts can be justified by an impact of the game on radiology learning or by the participation of a sector of students that is more active and motivated than the rest. Team results in the game showed moderate correlation with post-exposure tests but low correlation with course grades. The latter is reasonable, since the course has additional contents to those dealt with in the game (neuroimaging, head and neck, ultrasound, nuclear medicine, etc.) and all participants had access to formal teaching activities to prepare for the examination.

This study has several limitations. One is the possible demotivation and abandonment of participation in the game. The last three teams in the classification accumulated $76.2 \%$ of the undelivered weekly tests, and the last 
team did not turn in any of the N/P tasks. Perhaps it is better for students to propose all four members of their team rather than assigning pairs of students. It would be interesting to deepen the way in which students experience competition, since they are exposed to messages of social comparison that can influence their self-conception, emotions and actions [43], and pressure and anxiety about time spent playing, in conflict with other academic tasks, can inhibit participation and collaboration [44]. It would also be interesting to evaluate in depth the feeling of cooperation given and received, since the inhibition of a partner can modify the motivation of the team, or the role of leadership or mentor can modulate the cognitive process of their colleagues [45].

Technical limitations have been described as a factor that limits student participation in Second Life teaching activities [46, 47]. In other studies, on teaching radiology in Second Life to medical students, $9-11 \%$ of these expressed serious technical limitations [25, 27, 28]. In the present study, only one student reported on technical limitations and was able to participate in the game thanks to the help of his/her classmates, which expresses the collaborative nature of this edition by teams.

This study does not assess radiological anatomy and radiological semiology of neuroradiology, breast radiology, or vascular interventional radiology, which could be included in future activities of this project. One of the future perspectives of this project is to reproduce it with students from different universities since the adaptation of the rules of the game allows for an inter-university competition. This would reduce the proximity bias to analyse the perception of the participants, since in this study the positive evaluation of the experience could be influenced in part because it is conducted by the professor responsible for their formal Radiology course. Furthermore, the sense of belonging, competing with others at the national level, can have very motivating results, as other educational competitions with medical students have shown [48]. Competition with students from various medical schools could reach interesting heights. In a further step, cooperation with international universities would allow evaluating the results and limitations of the learning game in an international and multicultural setting.

\section{Conclusion}

A multi-user game to learn radiology in Second Life adapted to team competition has been very positively perceived by third-year medical students, who highly valued its content, organisation, and usefulness for their training. Most of the participants agreed that they had collaborated as a team and that playing in competitive environments helps them learn better. The best postexposure and academic results compared to non-participating students indicate the potential impact of the game on learning. This study lays the necessary foundations to repeat the competition with students from different medical schools.

\section{Abbreviations}

N/P: Normal or pathological; PDF: Portable document format.

\section{Supplementary Information}

The online version contains supplementary material available at https://doi. org/10.1186/s13244-021-01032-3.

Additional file 1. Appendix 1. Questionnaire. Appendix 2. Open-ended comments. Appendix 3. Correlation matrices of the questionnaire.

\section{Acknowledgements}

The authors would like to express their gratitude to the students who voluntarily participated in this edition of the League of Rays game.

\section{Authors' contributions}

TR-S performed study design, data collection and analysis, manuscript writing and edition. AJ-Z contributed to online game preparation and data collection. $\mathrm{RL}-\mathrm{A}$ and DD-P were involved in online game preparation and manuscript writing. MJR-G performed data analysis and manuscript edition; FS-P was involved in study design, online game preparation, data collection and analysis, statistical analysis, and manuscript writing and edition. All authors read and approved the final manuscript.

\section{Funding}

The Innovative Education Projects, \#PIE17-113 and \#PIE19-217, and the Department of Radiology and Physical Medicine of the University of Malaga partially supported this study. The maintenance cost of the Medical Master Island during this project was supported by the Andalusian Society of Radiology (Asociación de Radiólogos del Sur), a subsidiary of the Spanish Society of Radiology (SERAM).

Availability of data and materials

The datasets used and/or analysed during the current study are available from the corresponding author on reasonable request.

\section{Declarations}

Ethics approval and consent to participate

This study carried out within the framework of the Educational Innovation Project of the University of Malaga \# PIE17-113 received the corresponding approval from the Vice-Rector's Office for Teaching and Research Staff. The students gave their explicit consent when they voluntarily agreed to participate. No additional ethical permission was needed.

\section{Competing interests}

The authors declare that they have no competing interests.

\section{Author details}

${ }^{1}$ Department of Nuclear Medicine, University Hospital Virgen de Las Nieves, Granada, Spain. ${ }^{2}$ Department of Radiology and Physical Medicine, School of Medicine, University of Málaga, Málaga, Spain. ${ }^{3}$ Department of Emergency and Critical Care, Hospital de La Serranía, Ronda, Spain.

Received: 11 February 2021 Accepted: 2 June 2021

Published online: 29 June 2021 


\section{References}

1. European Society of Radiology (ESR) (2019) ESR statement on new approaches to undergraduate teaching in Radiology. Insights Imaging 10:109. https://doi.org/10.1186/s13244-019-0804-9

2. Janssen A, Shaw T, Goodyear P, Kerfoot P, Bryce D (2015) A little healthy competition: using mixed methods to pilot a team-based digital game for boosting medical student engagement with anatomy and histology content. BMC Med Educ 15:173. https://doi.org/10.1186/ s12909-015-0455-6

3. Akl EA, Pretorius RW, Sackett K et al (2010) The effect of educational games on medical students' learning outcomes: a systematic review: BEME Guide No 14. Med Teach 32:16-27. https://doi.org/10.3109/01421 590903473969

4. Graafland M, Schraagen JM, Schijven MP (2012) Systematic review of serious games for medical education and surgical skills training. Br J Surg 99:1322-1330. https://doi.org/10.1002/bjs.8819

5. Pitt MB, Borman-Shoap EC, Eppich WJ (2015) Twelve tips for maximizing the effectiveness of game-based learning. Med Teach 37:1013-1017. https://doi.org/10.3109/0142159X.2015.1020289

6. Pesare E, Roselli T, Corriero N, Rossano V (2016) Game-based learning and gamification to promote engagement and motivation in medica learning contexts. Smart Learn Environ 3:5. https://doi.org/10.1186/ s40561-016-0028-0

7. Sanchez E (2017) Competition and collaboration for game-based learning: a case study. In: Wouters $\mathrm{P}$, van Oostendorp $\mathrm{H}$ (eds) Instructional techniques to facilitate learning and motivation of serious games. Advances in game-based learning. Springer, Cham, pp 161-184. https:// doi.org/10.1007/978-3-319-39298-1_9

8. Van Nuland SE, Roach VA, Wilson TD, Belliveau DJ (2015) Head to head: the role of academic competition in undergraduate anatomical education. Anat Sci Educ 8:404-412. https://doi.org/10.1002/ase.1498

9. Jones D (2013) An alternative (to) reality. In: Childs M, Peachey A (eds) Understanding learning in virtual world, 1st edn. Springer, London, pp $1-20$

10. Potkonjak V, Gardner M, Callaghan V et al (2016) Virtual laboratories for education in science, technology, and engineering: a review. Comput Educ 95:309-327. https://doi.org/10.1016/j.compedu.2016.02.002

11. Zuiker SJ (2012) Educational virtual environments as a lens for understanding both precise repeatability and specific variation in learning ecologies. Br J Educ Technol 43:981-992. https://doi.org/10.1111/j.14678535.2011.01266.x

12. Olteanu RL, Bîzoi M, Gorghiu G, Suduc AM (2014) Working in the Second Life environment-a way for enhancing students' collaboration. Procedia Soc Behav Sci 141:1089-1094. https://doi.org/10.1016/j.sbspro.2014.05. 183

13. Pellas N, Mystakidis S (2020) A systematic review of research about gamebased learning in virtual worlds. J Univ Comp Sci 26:1007-1042

14. Liaw SY, Carpio GA, Lau Y, Tan SC, Lim WS, Goh PS (2018) Multiuser virtual worlds in healthcare education: a systematic review. Nurse Educ Today 65:136-149. https://doi.org/10.1016/j.nedt.2018.01.006

15. Rosal MC, Heyden R, Mejilla R et al (2014) A virtual world versus face-toface intervention format to promote diabetes self-management among African American women: a pilot randomized clinical trial. JMIR Res Protoc 3:e54. https://doi.org/10.2196/resprot.3412

16. Brewer LC, Kaihoi B, Zarling KK, Squires RW, Thomas R, Kopecky S (2015) The use of virtual world-based cardiac rehabilitation to encourage healthy lifestyle choices among cardiac patients: intervention development and pilot study protocol. JMIR Res Protoc 4:e39. https://doi.org/10. 2196/resprot.4285

17. Weiner E, Trangenstein $P_{1}$ McNew R, Gordon J (2016) Using the virtual reality world of second life to promote patient engagement. Stud Health Technol Inform 225:198-202. https://doi.org/10.3233/ 978-1-61499-658-3-198

18. Wiecha J, Heyden R, Sternthal E, Merialdi M (2010) Learning in a virtual world: experience with using second life for medical education. J Med Internet Res 12:e1. https://doi.org/10.2196/jmir.1337

19. Melús-Palazón E, Bartolomé-Moreno C, Palacín-Arbués JC et al. (2012) Experience with using second life for medical education in a family and community medicine education unit. BMC Med Educ 12:30. https://doi. org/10.1186/1472-6920-12-30
20. Creutzfeldt J, Hedman L, Felländer-Tsai L (2016) Cardiopulmonary resuscitation training by avatars: a qualitative study of medical students experiences using a multiplayer virtual world. JMIR Serious Game 4:e22. https://doi.org/10.2196/games.6448

21. Richardson A, Hazzard M, Challman SD, Morgenstein AM, Brueckner JK (2011) A "Second Life" for gross anatomy: applications for multiuser virtual environments in teaching the anatomical sciences. Anat Sci Educ 4:39-43. https://doi.org/10.1002/ase.195

22. Gazave CM, Hatcher AR (2017) Evaluating the use of Second Life ${ }^{T M}$ for virtual team-based learning in an online undergraduate anatomy course. Med Sci Educ 27:217-227. https://doi.org/10.1007/s40670-017-0374-8

23. Sendra-Portero F, Lorenzo-Alvarez R, Pavia-Molina J (2018) Teaching radiology in the "Second life" virtual world. Diagn Imag Eur 34:43-45

24. Lorenzo Álvarez R, Pavia-Molina J, Sendra-Portero F (2018) Possibilities of the three-dimensional virtual environment tridimensional Second Life ${ }^{\circledR}$ for training in radiology. Radiologia 60:273-279. https://doi.org/10.1016/j. rx.2018.02.006

25. Lorenzo-Alvarez R, Pavia-Molina J, Sendra-Portero F (2018) Exploring the potential of undergraduate radiology education in the virtual world Second Life with first-cycle and second-cycle medical students. Acad Radiol 25:1087-1096. https://doi.org/10.1016/j.acra.2018.02.026

26. Lorenzo-Alvarez R, Ruiz-Gomez MJ, Sendra-Portero F (2019) Medical students' and family physicians' attitudes and perceptions toward radiology learning in the virtual world Second Life. AJR Am J Roentgenol 212:1295-1302. https://doi.org/10.2214/AJR.18.20381

27. Lorenzo-Alvarez R, Rudolphi-Solero T, Ruiz-Gomez MJ, Sendra-Portero $F$ (2019) Medical student education for abdominal radiographs in a 3D virtual classroom versus traditional classroom: a randomized controlled trial. AJR Am J Roentgenol 213:644-650. https://doi.org/10.2214/AJR.19. 21131

28. Lorenzo-Alvarez R, Rudolphi-Solero T, Ruiz-Gomez MJ, Sendra-Portero F (2020) Game-based learning in virtual worlds: a multiuser online game for medical undergraduate radiology education within Second Life. Anat Sci Educ 13:602-617. https://doi.org/10.1002/ase.1927

29. Paas F, van Merriënboer JJG (1994) Instructional control of cognitive load in the training of complex cognitive tasks. Educ Psychol Rev 6:51-71. https://doi.org/10.1007/BF02213420

30. Saldaña J (ed) (2013) The coding manual for qualitative researchers, 2nd edn. Sage Publications Ltd, London

31. Vogelsang M, Rockenbauch K, Wrigge H, Heinke W, Hempel G (2018) Medical Education for "Generation Z": Everything online?!- an analysis of Internet-based media use by teachers in medicine. GMS J MedEduc 35:21. https://doi.org/10.3205/zma001168

32. Kron FW, Gjerde CL, Sen A, Fetters MD (2010) Medical student attitudes toward video games and related new media technologies in medical education. BMC Med Educ 10:50. https://doi.org/10.1186/ 1472-6920-10-50

33. Richardson-Hatcher A, Hazzard M, Ramirez-Yanez G (2014) The cranial nerve skywalk: a 3D tutorial of cranial nerves in a virtual platform. Anat Sc Educ 7:469-478. https://doi.org/10.1002/ase.1445

34. Awan O, Dey C, Salts H et al (2019) Making learning fun: gaming for radiology education. Acad Radiol 26:1127-1136. https://doi.org/10.1016/j. acra.2019.02.020

35. Toro-Troconis M, Meeram M, Higham J, Mellström U, Partridge M (2010) Design and delivery of game.based learning for virtual patients in Second Life: initial findings. In: Peachey A, Gillen J, Livingstone D, Smith-Robbins S (eds) Researching learning in virtual worlds. Human computer interaction series. Springer, London, pp 111-138

36. Toro-Troconis M, Mellström U (2010) Game-based learning in Second Life $^{\circledR}$. Do gender and age make a difference? J Gaming Virt World 2:53-76. https://doi.org/10.1386/jgvw.2.1.53_1

37. Vallance AK, Hemani A, Fernandez V, Livingstone D, McCusker K, ToroTroconis M (2014) Using virtual worlds for role play simulation in child and adolescent psychiatry: an evaluation study. Psychiatr Bull 38:204-210. https://doi.org/10.1192/pb.bp.113.044396

38. Vavasseur A, Muscari F, Meyrignac O et al (2020) Blended learning of radiology improves medical students' performance, satisfaction, and engagement. Insights Imaging 11:61. https://doi.org/10.1186/ s13244-020-00865-8

39. Eisen LA, Berger JS, Hegde A, Schneider RF (2006) Competency in chest radiography. A comparison of medical students, residents, and fellows. J 
Gen Intern Med 21:460-465. https://doi.org/10.1111/j.1525-1497.2006. 00427.x

40. Delrue L, Gosselin R, Ilsen B, Van Landeghem A, de Mey J, Duyck P (2011) Difficulties in the interpretation of chest radiography. In: Coche EE, Ghaye B, de Mey J, Duyck P (eds) Comparative interpretation of CT and standard radiography of the chest, 1st edn. Springer, Heidelberg, pp 27-49

41. Johnson D, Johnson R, Smith K (1995) Cooperative learning and individual student achievement in secondary schools. In: Pedersen JE (ed) Secondary schools and cooperative learning: theories, models, and strategies. Garland Publishing, New York, pp 3-54

42. Corell A, Regueras LM, Verdú E, Verdú MJ, de Castro JP (2018) Effects of competitive learning tools on medical students: a case study. PLoS One 13:e0194096. https://doi.org/10.1371/journal.pone.0194096

43. Gilbert DT, Giesler RB, Morris KA (1995) When comparisons arise. J Pers Soc Psychol 69:227-236. https://doi.org/10.1037//0022-3514.69.2.227

44. Van Eck R, Dempsey J (2002) The effect of competition and contextualized advisement on the transfer of mathematics skills a computer-based instructional simulation game. Educ Technol Res Dev 50:23-41. https:// doi.org/10.1007/BF02505023
45. Ke F (2008) Computer games application within alternative classroom goal structures: cognitive, metacognitive, and affective evaluation. Educ Technol Res Dev 56:539-556. https://doi.org/10.1007/s11423-008-9086-5

46. Baker SC, Wentz RK, Woods MM (2009) Using virtual worlds in education: Second Life as an educational tool. Teach Psychol 36:59-64. https://doi. org/10.1080/00986280802529079

47. Gong W (2018) Education and three-dimensional virtual worlds: a critical review and analysis of applying second life in higher education. Master of Education Dissertation, University of British Columbia

48. Jiang G, Chen H, Wang Q et al (2016) National Clinical Skills Competition: an effective simulation-based method to improve undergraduate medical education in China. Med Educ Online 21:29889. https://doi.org/10. 3402/meo.v21.29889

\section{Publisher's Note}

Springer Nature remains neutral with regard to jurisdictional claims in published maps and institutional affiliations.

\section{Submit your manuscript to a SpringerOpen ${ }^{\odot}$ journal and benefit from:}

- Convenient online submission

- Rigorous peer review

- Open access: articles freely available online

- High visibility within the field

- Retaining the copyright to your article

Submit your next manuscript at $\boldsymbol{\nabla}$ springeropen.com 